\title{
Economic footprint of California wildfires in 2018
}

\author{
Daoping Wang ${ }^{1,9}$, Dabo Guan ${ }^{2,3, *, 9}$, Shupeng Zhu ${ }^{4}$, Michael MacKinnon ${ }^{4}$, Guannan Geng ${ }^{5}$, \\ Qiang Zhang ${ }^{2}$, Heran Zheng ${ }^{6}$, Tianyang Lei ${ }^{2}$, Shuai Shao ${ }^{7,1}$, Peng Gong ${ }^{2}$, and Steven J. \\ Davis $^{8}$
}

\footnotetext{
${ }^{1}$ School of Urban and Regional Science, Shanghai University of Finance and Economics, Shanghai, China.

${ }^{2}$ Department of Earth System Science, Tsinghua University, Beijing, China.

${ }^{3}$ The Bartlett School of Construction and Project Management, University College London, London, UK.

${ }^{4}$ Advanced Power and Energy Program, University of California, Irvine, Irvine, CA, USA.

${ }^{5}$ State Key Joint Laboratory of Environmental Simulation and Pollution Control, School of Environment, Tsinghua University, Beijing, China.

${ }^{6}$ Industrial Ecology Programme, Norwegian University of Science and Technology, Trondheim, Norway.

${ }^{7}$ School of Business, East China University of Science and Technology, Shanghai, China.

${ }^{8}$ Department of Earth System Science, University of California, Irvine, Irvine, CA, USA.

${ }^{9}$ These authors contributed equally.
}

*Corresponding email: guandabo@tinghua.edu.cn 


\section{Abstract}

Recent increases in the frequency and scale of wildfires worldwide have raised concerns about the influence of climate change and associated socio-economic costs. In the western U.S., the hazard of wildfire has been increasing for decades. Here, we use a combination of physical, epidemiological, and economic models to estimate the economic impacts of California wildfires in 2018, including the value of destroyed and damaged capital, the health costs related to air pollution exposure, and indirect losses due to broader economic disruption cascading along with regional and national supply chains. Our estimation shows that wildfire damages in 2018 totaled \$148.5 (126.1-192.9) billion (roughly $1.5 \%$ of California's annual GDP), with $\$ 27.7$ billion (19\%) in capital losses, $\$ 32.2$ billion (22\%) in health costs, and $\$ \mathbf{8 8 . 6}$ billion $(59 \%)$ in indirect losses. Our results reveal that the majority of economic impacts related to California wildfires may be indirect and often affect industry sectors and locations distant from the fires (e.g., 52\% of the indirect losses-31\% of total losses-in 2018 were outside of California). Our findings and methods provide new information for decision-makers tasked with protecting lives and key production sectors and reducing the economic damages of future wildfires.

The frequency and size of wildfires in the western U.S. has been increasing for several decades, driven by climate change-related decreases in precipitation and related changes in the moisture in vegetation ${ }^{1-5}$. Meanwhile, land and fire management have likely exacerbated the hazard ${ }^{6}$, and population and economic growth - especially at the wildland-urban interface ${ }^{7}$ - have dramatically increased the human exposure to fires. The combined result has been ever rising wildfire risks, culminating in California in a series of enormously damaging fires in 2017 and 2018. To date, efforts to quantify the impacts of specific fires on humans (e.g., by researchers, but also by insurance companies, public agencies, and the media) have focused on the physical and direct damage to infrastructure and loss of life ${ }^{8}$. The potential human health effects of wildfire smoke is also increasingly recognized, but only rarely estimated ${ }^{9,10}$. But disasters may also have large indirect impacts on economic activities that extend much beyond the location of physical destruction or smoke ${ }^{11-13}$. For example, destruction of productive capital, interruption of transportation systems, or labor supply affects other economic activities up and down all connected supply chains. Such economic disruption by fires has never been quantified; our understanding of the magnitude of wildfire impacts and their distribution across space and industries may thus be badly incomplete. In turn, decision makers (including government officials, businesses, and residents) may systematically underestimate wildfire risks and thereby misallocate resources intended to recover from past fires and/or build up resilience to future ones. 
Here, we use a combination of approaches to evaluate the full economic footprint of California wildfires that occurred in 2018. These fires were the deadliest and one of the most destructive of any year in California history: 8,527 fires burned an area of 1.9 million acres $\left(7,700 \mathrm{~km}^{2} \text {; approaching } 2 \% \text { of the state's area }\right)^{14}$. Table 1 lists the 17 largest fires by area burned, along with their location in the state and duration. Details of our analytical approach and data sources are provided in the Methods section. In summary, we estimate capital losses as the costs to repair and rebuild damaged or destroyed assets based on data from the U.S. National Interagency Fire Center's Large Incident Year-to-Date Report ${ }^{14}$ and valuations compiled from insurance companies (e.g., Munich $\mathrm{RE}^{15}$ ). We then estimate morbidity, mortality, and health cost (e.g., medical expenses, lost working time, etc.) related to fire-related air pollution using the most up-to-date emissions inventory from the fourth-generation global fire emissions database (GFED4) ${ }^{16}$, a regional chemical transport model (developed based on the state-of-the-science model GEOS-Chem), and the U.S. Environmental Protection Agency's (EPA) Benefits Mapping and Analysis Program (BenMAP) ${ }^{17}$. Finally, we estimate indirect losses of economic disruption to 80 industry sectors in each of California's 58 counties and the rest of the U.S. using the multiregional disaster footprint model ${ }^{18-20}$ (see Methods).

\section{Results}

Figure 1 shows modeled results of monthly-average PM2.5 concentrations related to California wildfires between July and December of 2018 along with the corresponding areas of California with unhealthy air quality. Major fires in July occurred in both the northern parts of the state (e.g., the Pawnee, Klamathon, Carr, and Mendocino Complex, and Whaleback fires; see Table 1 and Supplementary Figure 1) and the Sierra Nevada (e.g., the Lions and Ferguson fires) (Fig. 1a). Altogether, fires destroyed 472 structures in July, and negatively affected air quality throughout much of the northern half of the state, especially in Shasta, Glenn, and Tehama counties in the north and Mariposaa, Tuolumne, and Madera counties in the Sierra Nevada (Table 1; Fig. 1a). At the worst, on July 30, the air quality of over 39 million acres was categorized as unhealthy or worse - roughly $31 \%$ of the state's area, and $31 \%$ of the state's population lives in these areas. Many of the fires which began in July or even June of 2018 were still burning and spreading in August, when still more fires started both in the north (e.g., the Hirz and Stone fire; see Table 1) and the Sierra Nevada (e.g., the Donnell fire), as well as in the southern parts of the state (e.g., the Holy fire; Fig. 1b). The fires destroyed an additional 1,618 structures in August, and further degraded air quality over an even larger area: as of August 5, air quality of 36 million acres was categorized as unhealth or worse (29\% of the state's area, $25 \%$ of the state's population lives in these area; Fig. 1b). All the major fires begun prior to September ended in early September due to increases of precipitation, and the Delta 
fire in Shasta county was the only new major fire that began in September (on the $5^{\text {th }}$ ). As a result, fire-related air pollution was much lower in September; at the worst, unhealthy air spanned 6.95 million acres in the northernmost part of the state on September $7^{\text {th }}$ (5.6\% of the state's population lives in these area; Fig. 1c). The Delta fire destroyed 45 structures, and was not fully contained until October $6^{\text {th }}$. The break in major fires continued throughout October, such that fire-related air pollution remained low (Fig. 1d). On November $8^{\text {th }}$ we saw the start of the last two major fires of the year, the Camp in northern California and the Woolsey in southern California, which contributed to the destruction of 20,447 structures in November. These fires also substantially degraded air quality throughout the northern Central Valley, Bay Area, and north coast counties; on November 17, air quality was categorized as unhealthy or worse over 18.61 million acres (39.0\% of the state's population lives in these areas; Fig. 1e).

Figure 2 shows our estimates of fire-related damages from the 2018 fires in total and broken down by capital losses, health costs, and indirect losses of economic disruption (mean results of the sensitivity analysis; see table $\mathrm{S} 1$ for county-level damages in each category). Of $\$ 27.7$ billion in capital losses, $\$ 4.5$ billion (17\%) belonged to households and $\$ 23.2$ billion (83\%) were productive capital, i.e., commercial, industrial, or public assets. The greatest capital losses of any individual fire were those related to the Camp fire in Butte county, which totaled \$14.6 billion (53\% of all capital losses; Supplementary Figure 2). This helps to explain the disproportionately large capital losses in the northern parts of the state, with Ventura and Los Angeles counties showing up as southern hotspots of capital losses (Fig. 2a). Given the larger populations of these southern counties, per capita capital losses were not as great, however (Fig. 2b). Health costs fall into three categories: mortality, medical expenses, and work time lost. Mortality dominates the total. We estimate 3,652 air pollution deaths were caused by California's 2018 fires which — applying the value of statistical life - represent a loss of $\$ 32.2$ billion. It should be noted that the deaths related to air pollution are considerably greater than the reported 104 lives (including 98 civilians and 6 firefighters) that were claimed directly by the fires. In comparison to the deaths, the costs related to medical expenses and work time lost are relatively small: $\$ 210$ million and $\$ 130$ million, respectively. The geographical distribution of the health costs reflect a combination of the areas most affected by wildfire-related $\mathrm{PM}_{2.5}$ (Fig. 1) and populated areas. Thus, overall health costs in the Bay Area and Sacramento-San Joaquin Delta and Los Angeles metropolitan area are particularly large — despite the fact that some of the affected counties had no major fires (Fig. 2c; Table 1). In contrast, per capita health costs more closely reflect the highest concentrations of wildfire-related $\mathrm{PM}_{2.5}$ (Figs. $2 \mathrm{~d}$ and 1).

Our estimates of indirect losses caused by fire-related economic disruptions in 2018 are considerably larger than either direct capital losses or health costs. Total losses in the U.S. were $\$ 88.6$ billion - more than $0.4 \%$ of the nation's GDP that year. Of this total, $\$ 42.7$ billion $(48.2 \%)$ of the indirect losses occurred in California and $\$ 45.9$ billion (51.8\%) occurred in 
other parts of the U.S. via production and consumption supply chains connected to California. Despite having no major fires itself, Sacramento county suffered the greatest indirect losses, $\$ 6.6$ billion ( $8 \%$ of the county's GDP that year; Supplementary Table 1). But as a share of GDP, Butte county (where the Camp fire occurred in November) suffered even greater indirect losses: $\$ 5.6$ billion, or $47.4 \%$ of its own GDP. Combining the damages in all categories, the geographical distribution of total losses are substantial in many California counties, though often for different reasons (Fig. 2g; Supplementary Figure 2). Total losses were again largest in Butte county ( $\$ 23.2$ billion), followed by Sacramento and Los Angeles counties ( $\$ 10.1$ and $\$ 9.1$ billion, respectively; Supplementary Table 1). Per capita losses highlight areas with relatively low populations but large losses; in Butte, Shasta, and Lake counties, damages were \$101 thousand, \$35 thousand and \$13 thousand per capita (Fig. 2h; Supplementary Table 1).

The ternary plots in Figure 3 shows the magnitude of 2018 fire impacts on specific industry sectors in California (size of circles) as well as the relative shares of capital losses, health costs, and indirect losses (position of circles; see also Supplementary Table 2). The service industry suffered the greatest total losses ( $\$ 44.4$ billion, or $45.1 \%$ of the statewide total), with $44.7 \%$ of this total related to health costs, $33.8 \%$ related to capital losses, and $21.5 \%$ associated with indirect losses (red circle in Fig. 3a). In contrast, $78.1 \%$ of damages to the manufacturing sector (second largest at $\$ 22.3$ billion, $22.6 \%$ of total losses) indirect losses, with just $15.7 \%$ in health costs, and $6.2 \%$ in capital losses (turquoise circle in Fig. 3a). Combined losses in all of the other five major sectors were $\$ 31.7$ billion (Fig. 3a). Yet, breaking damages into subsectors, we see the composition of damages varies widely. For example, in the service sector, damages to the real estate industry were heavily concentrated in capital losses $(77.2 \%$ of the subsector's $\$ 9.3$ billion in damages) as opposed to mostly health costs in labor-intensive subsectors such as education, software, and restaurants (Fig. 3b) and trade (i.e. retail) subsectors (Fig. 3d). Damages to some manufacturing subsectors were also mostly health costs (e.g., the aircraft, medical and electrical industries), but overall damages are dominated by indirect losses related to the chemical industry (Fig. 3c). Chemical industry is the largest manufacturing sector in Califonia, which contributes about $3.7 \%$ of overall statewide GDP. The figure in some counties, such as Solona and Contra Costa, accounts for 25\%-29\% of county-level industrial outputs. During the fire events, chemical industry suffered direct capital loss of $\$ 284.5$ million and health costs of $\$ 375.1$ million, but the changes of demand and supply patterns in chemical production chains caused indirect loss with the state of $\$ 13,639.3$ million and out of state of $\$ 2,513.1$ million. Supplementary Figures 4-7 and Supplementary Table 2 show and further explored subsector results for each of the other major sectors.

Uncertainties. Sensitivity analysis of parameters in epidemiological model. We perform a Monte-Carlo analysis with BenMAP-CE to quantify the 95\% confidence interval (CI) around the mean incidence and valuation estimates. Although long-term changes in $\mathrm{PM}_{2.5}$ exposure dominate the valuation impacts, we report results for both short-term and long-term exposure related to the 2018 wildfire episodes. Consistent with the current modeling methods practiced 
by regulatory agencies including the U.S. EPA and South Coast Air Quality Management District, no concentration threshold is assumed for the health impact assessment modeling ${ }^{21}$. Statewide, mean health costs of the fires are $\$ 32.15$ billion and $95 \%$ confidence interval range from $\$ 13.33$ billion to $\$ 75.92$ billion). The range of uncertainty in our valuation is generally consistent with other BenMAP estimates reported in the literature and relates to statistical error and cross-study variability ${ }^{21-23}$.

Uncertainties in capital damage statistics. The uncertainty in capital damage statistics is mostly related to the degree of building losses and their reconstruction costs. Since the degree of damage to affected buildings is not given by official reports, we assume the average damage proportion is $50 \%$, but with a range uniformly distributed from $1 \%$ to $99 \%$. For the reconstruction cost of buildings in different region in California, we refer to values reported by Allstate, CoreLogic, and reinsurance companies (i.e., Munich $\mathrm{RE}^{15}$ ). These companies Insurance Journal reports provide the number and total reconstruction cost value of buildings within the perimeters of the major fires. We then calculate the average reconstruction cost of the buildings in different region using these valuations. We find an average reconstruction cost for residential buildings of $\$ 238,600$ in the Camp fire area, and \$695,500 in the Woolsey fire area. For commercial buildings, the average is $\$ 2.69$ million in the Camp fire area, and \$1.04 million in the Woolsey fire area. We use these two fires to bound building reconstruction costs in other regions, randomly selecting from the full range for Monte Carlo simulations to create a distribution of capital losses. In this way, we find the average total damage to residential buildings is $\$ 4.52$ billion, with a $95 \%$ confidence interval from $\$ 3.13$ billion to $\$ 7.49$ billion, and the average total damage to commercial buildings is $\$ 23.2$ billion, with a $95 \%$ confidence interval from $\$ 15.78$ billion to $\$ 29.62$ billion.

Sensitivity analysis of parameters in economic model. There are two main parameters in the economic model that will bring uncertainty to the results. One is the reconstruction time of the building, and the other is the time of traffic recovery in the fire area. We assume the average recovery time of a building is 90 days, i.e., it takes 90 days from the acquisition of recovery resources to complete rebuilding. This rebuilding time parameter is then varied from 60 days to 120 days in our sensitivity analysis. Similarly, we assume that the average recovery time of transportation in a fire area was 14 days after the fire was contained, and vary this parameter from 7 days and 21 days in the sensitivity analysis. In this way, we find that the average production loss is $\$ 88.61$ billion, ranging from $\$ 79.40$ billion to $\$ 96.05$ billion.

Sensitivity analysis of total economic footprint. Using the distribution of losses obtained by our three type of losses uncertainty analysis, we perform 2000 simulations in our Monte Carlo analysis to generate a distribution of the total economic footprint of California wildfires in 
2018. Supplementary Figure 8 shows the resulting distribution of total fire losses along with $95 \%$ confidence intervals: 148.5 billion, ranging from $\$ 126.07$ billion to $\$ 192.93$ billion.

\section{Discussion}

Although substantial, the direct capital losses related to the 2018 California wildfires represent only $27.0 \%$ of the statewide total damages we estimate in this study, and an even smaller share of the impacts in some counties and to specific industry sectors. Health costs and indirect economic losses, rarely if ever quantified before, represent an enormous $31.5 \%$ and $41.5 \%$ of the statewide total damages, respectively. Moreover, these indirect impacts in some case fell heavily on locations (e.g., Sacramento county) and industries (e.g., chemical manufacturing) away from major fires. In the same way, our results reveal that the U.S. beyond California also suffered considerable economic damages ( $\$ 45.9$ billion) related to California's wildfires. Quantifying and mapping these less obvious but large damages in 2018 leads to the conclusion that large wildfires occurring in California or other western states are not isolated problems. Although the horrific scenes of death and destruction may seem confined to specific communities, the related economic and health impacts affect a much broader area, which in 2018 included substantial losses to the national economy. Recognizing the full magnitude and scope of wildfires' economic footprint may in turn influence decision-making about land and forest management, fire suppression efforts, and development patterns. For example, health costs and indirect losses of future fires might be reduced by focusing fire prevention efforts on areas typically upwind of major population centers or near important industrial or transportation infrastructure. Similarly, our results suggest that the indirect economic losses related to the recent forced electricity outages ${ }^{24,25}$ might be much larger than the capital losses that may have been avoided (though lives may have been saved).

The magnitude and spatial distribution of wildfire impacts support greater investments in fire prevention and suppression, including investments by jurisdictions indirectly affected by the related pollution and economic disruption. Our work forcefully demonstrates that the impacts of wildfires are much more broadly distributed in space than conventional wisdom might suggest. Now and as the climate changes, wildfire risks transcend far beyond the wildland-urban interface, they are a statewide and regional challenge. In turn, recognizing the greater magnitude and far-reaching indirect impacts of the recent fires may justify dedicating substantially greater resources to mitigate fire risks and coordinating planning and responses across the state and region.

However, our estimates of wildfire-related damages in 2018 are subject to some important uncertainties, and our methods may not capture all types of economic damages. For example, the reconstruction cost value of buildings damaged in fire events and to be restored after the disaster are based on average estimates of each fire region, rather than specific marketing information. Similarly, estimates of health costs assume methods that reasonably account for statistical uncertainties but may understate the impact of epistemic uncertainties, including 
those associated with air quality modeling, epidemiological science, and health economic valuation $^{26}$. Furthermore, only impacts to California populations are quantified though intrastate transport of pollutants may accrue health costs elsewhere. Time lags between the fires and the restoration of transportation lines, as well as the time require to rebuild are the key uncertain parameters in estimating indirect losses. Our analysis also neglects international trade and difficult-to-quantify impacts such as effects on mental health and the prospect of cascading events such as subsequent landslides. Unfortunately, indirect economic costs are extraoridinarily difficult to validate ${ }^{11,18}$ because models such as ours focus on estimating firerelated supply-chain losses assuming that the myriad other factors that affect economic growth do not change, but the reality is that many such other factors will have changed, and the growth of the state's GDP will be the net of all these changes. In an effort to quantify some of the uncertainties, we conducted a sensivitity analysis for each of three models used in the study and integrated the results into a single uncertainty analysis of the overall economic footprints. Details are available in the Methods and Supplementary Information. Despite the uncertainties, projected climate change, population growth, and economic development will continue to increase wildfire risks in California and the rest of the western U.S. in the years and decades to come. Understanding the economic footprint of past fires can only help in strategically confronting these risks so as to cost-effectively minimize the impacts of future fires.

\section{Methods}

Definition of the economic footprint of wildfires. The economic footprint of a wildfire provides a comprehensive accounting of the wildfire-induced both direct and indirect economic losses in our socio-economic system. The economic footprint of a wildfire consist of (i) the direct capital cost, i.e., the repairing or reconstruction cost of the assets that have been damaged or destroyed in the wildfires; (ii) the health cost, i.e., medical costs, working time loss and mortality rising, due to air pollution-induced by wildfires; (iii) the indirect cost, i.e., the potential value-added losses of the economy due to the supply-chain disruptions triggered by wildfires. Note that, the indirect part of the economic footprint of wildfires was designed to estimate the potential supply-chain losses related to the wildfires assuming that other factors do not change. As such, the analytical framework is fundamentally different from those used in other macroeconomic analyses that aim to simulate and project real changes in an economy.

Supplementary Figure 9 shows the overall analytical framework for economic footprint accounting. A random forest model was used to estimate the daily mean PM2.5 concentration at $4 \mathrm{~km}$ spatial resolution over California (Supplementary Fig. 9a). Then, we use two GEOSChem simulations (without- and with fire emissions) to calculate the fraction of wildfire induced-PM2.5 emission (Supplementary Fig. 9b). With the estimated gridded pollutant 
concentration data and population density data as inputs, we use the environmental Benefits Mapping and Analysis Program-Community Edition (BenMAP-CE) version 1.5 to assess the health-related socio-economic costs attributable to the degradation of air quality from wildfire emissions (Supplementary Fig. 9c). On the other hand, we estimated the losses of capital stock, both productive capital and residential building losses, according to reports on fires by CAL Fire and reports on reconstruction cost by insurance companies (Supplementary Fig. 9d). Finally, we use a Multiregional Disaster Footprint (MRDF) model to simulate the ripple effect of fire-induced production time loss, capital loss, and traffic disruption on supply-chain networks, and assess indirect economic losses (Supplementary Fig. 9e).

Wildfire-induced air pollution estimation. Daily mean $\mathrm{PM}_{2.5}$ concentrations at $4 \mathrm{~km}$ spatial resolution over California used in this study were estimated using random forest models that incorporated information from multiple sources, including ground measurements, satellite remote sensing, chemical transport model simulations, meteorological fields and land use variables. This method was widely used in previous studies on estimating high-resolution full-coverage $\mathrm{PM}_{2.5}$ concentrations (e.g., Xiao et al. ${ }^{27}$ ) and was able to capture large fire events $^{28}$.

Ground-level PM2.5 measurements for 2018 were obtained from the U.S. Environmental Protection Agency's Air Quality System (web links can be found at Data availability). Satellite-based aerosol optical depth (AOD) data retrieved by the Multi-angle Implementation of Atmospheric Correction (MAIAC) algorithm at $1 \mathrm{~km}$ spatial resolution ${ }^{29,30}$ based on the Moderate Resolution Imaging Spectroradiometer (MODIS) were downloaded from NASA Earthdata portal. PM2.5 simulations from the Modern-Era Retrospective analysis for Research and Applications, Version 2 (MERRA2) at $0.5^{\circ} \times 0.625^{\circ}$ resolution were also used in this study as additional information on PM2.5 distribution. Other variables compiled in this study included: pressure, temperature, wind speed, specific humidity, precipitation, shortwave and longwave fluxes, and evaporation at $\sim 13 \mathrm{~km}$ spatial resolution from the North American Land Data Assimilation Systems, elevation at $30 \mathrm{~m}$ spatial resolution from the National Elevation Data set (NED), forest cover, shrub cover and cultivated land cover at 30 m spatial resolution from the 2011 National Land Cover Database (NLCD), road lengths of major roads, highways and interstate highways extracted from ESRI StreetMap USA (Environmental Systems Research Institute, Inc., Redland, CA), and population data from 2017 LandScan data. All data were integrated into the $1 \mathrm{~km}$ MAIAC grid and the PM2.5 concentrtaions were first estimated at $1 \mathrm{~km}$ and then aggregated into $4 \mathrm{~km}$ grid.

Generally, random forest algorithm is an ensemble learning method based on decision trees, which has the advantage of allowing both continuous and categorical input variables and are quite robust to outliers. It also provides variable importance rankings as well as out- 
of-bag errors for variable selection and model evaluation. We built two random forest models in this study (i.e., with and without satellite inputs), and then merged their predictions together to obtain full spatial and temporal coverage of $\mathrm{PM}_{2.5}$ data, since AOD has missingness in certain time and places. Our models produce good results, with out-of-bag $\mathrm{R}^{2}$ of 0.83 and 0.80 for the two models, respectively.

When using AOD to estimate PM2.5 concentrations, statistical models (e.g., multi linear regression, geographically weighted regression, generalized additive model) or machine learning models were built to explain the spatial-temporal varied relationship between AOD and $\mathrm{PM}_{2.5}$ at locations where $\mathrm{PM}_{2.5}$ monitors are available, as shown below:

$$
P M_{2.5, o b s}=f(A O D, \text { ancillary data })
$$

where the independent variable $\mathrm{PM}_{2.5, \text { obs }}$ is $\mathrm{PM}_{2.5}$ observations; AOD is the satellite AOD at corresponding locations; ancillary data includes meteorological conditions, land use variable and other parameters that could influence the relationship between AOD and PM2.5. Then $\mathrm{PM}_{2.5}$ concentrations outside monitoring locations could be predicted by AOD and the ancillary data. Since AOD is randomly missing due to cloud cover and snow cover, we also built a model using MERRA-2 data at locations where AOD are unavailable:

$$
P M_{2.5, \text { obs }}=f\left(P M_{2.5, \text { MERRA }-2}, \text { ancillary data }\right)
$$

Results from the two models are merged to get the final results without double-counting.

It is worth noting that this method provides total surface $\mathrm{PM}_{2.5}$ from all emission sources but cannot identify the part specifically contributed by wildfire emissions. We therefore use a second model (GEOS-Chem) to simulate the fraction of $\mathrm{PM}_{2.5}$ induced by wildfires in total $\mathrm{PM}_{2.5}$. To calculate the wildfire-induced $\mathrm{PM}_{2.5}$ fractions, we used two GEOS-Chem model scenarios-with and without fire emissions. The differences between these two scenarios divided by the total $\mathrm{PM}_{2.5}$ were calculated as the wildfire $\mathrm{PM}_{2.5}$ fractions. The fire emissions used in this study were GFED4s emissions ${ }^{16}$. The GFED4 emissions used in this study are at spatial resolution of $0.25^{\circ} \times 0.25^{\circ}$ and temporal resolution of 3-hourly. Our global GEOSChem model has a spatial resolution of $2^{\circ} \times 2.5^{\circ}$. The transport/convection timestep in the model is 600 seconds and chemistry/emission timestep is 1200 seconds. Secondary organic aerosols are included in our model with the simple SOA scheme that provides the correct amount of global SOA without detailed chemistry.

Health impact assessment. A deep breadth of scientific literature demonstrates a positive association between exposure to ambient outdoor air pollution and increases in the incidence of morbidity and mortality within exposed populations ${ }^{31-33}$. Health-related socio-economic costs attributable to the degradation of air quality from wildfire emissions was assessed using 
the environmental Benefits Mapping and Analysis Program - Community Edition (BenMAP$\mathrm{CE}$ ) version $1.5^{17}$. BenMAP-CE is an open-source software developed by the US Environmental Protection Agency and is widely used in emission regulation assessment ${ }^{34,35}$ and wildfire health impact evaluation ${ }^{36,37}$. BenMAP applies the relationship between the pollution and certain health effects which is often referred to as the health impact function or the concentration-response (C-R) function (derived from Epidemiology studies; Supplementary Figure 10). The variables that appear in health impact functions are the following ones:

- Air Quality Change (Delta): The air quality change is the difference between the starting air pollution level (baseline) and the air pollution level after some change (control).

- Health Effect Estimate $(\beta)$ : It is an estimate of the percentage change in the risk of an adverse health effect due to changes in ambient air pollution. Effect estimates are obtained from epidemiology studies.

- Exposed Population: The exposed population is the number of people which are in the region where we are assessing the air pollution reduction.

- Health Baseline Incidence: The health incidence rate is an estimate of the average number of people who die (or suffer from some adverse health effect) in a given population over a given period of time.

BenMAP also calculates the economic value of avoided health effects. After calculating the health changes, you can estimate the economic value by multiplying the reduction of the health effect by an estimate of the economic value per case, which is obtained from health economic studies. In Supplementary Figure 11 you have a flow diagram where it is resumed all the data needed to obtain final monetary benefit results.

BenMAP-CE utilizes as an input the concentration differences resolved at the 24 hour timestep for $\mathrm{PM}_{2.5}$ between the baseline (without-wildfire) and the control case (withwildfire) determined in Methods Section 3 (with daily based concentration). Population projections are based on suggested BenMAP practices using Landscan data at $1 \mathrm{~km}$ spatial resolution ${ }^{38}$ for the year 2018 , and downscaled to the $4 \mathrm{~km}$ study domain using geospatial modeling. Baseline incidence rates at the county level by five-year age groups are obtained as appropriate for the current California population, and include estimates from public administrative records when possible ${ }^{39}$. Concentration-response (C-R) functions are used to quantify the increased incidence of mortality and morbidity endpoints resulting from increases in $\mathrm{PM}_{2.5}$ and are selected from a systematic review of the epidemiological literature accounting for applicability criteria including (amongst others) study date and design and geography and population characteristics ${ }^{40,41}$. For example, all-cause mortality effects 
associated with increases in annual $\mathrm{PM}_{2.5}$ exposure were quantified by pooling $\mathrm{C}-\mathrm{R}$ functions from Jerrett et al. ${ }^{42}$ and Krewski et al. ${ }^{43}$. We utilize baseline incidence rates for mortality provided by the South Coast Air Quality Management District taken from local health data based on public administrative data wherever possible (SCAQMD, 2016), and then calculate the additional incidence occurring from increased pollutant exposure. Socio-economic costs are then estimated using willingness-to-pay and cost-of-illness valuation functions from a survey of health economic literature for mortality and morbidity ${ }^{44,45}$. The value of statistical life selected for application with avoided incidents of mortality was $\$ 9$ million as a midpoint of a range of $\$ 4.2$ to $\$ 13.7$ million from Robinson and Hammitt ${ }^{46}$, all expressed in 2013 dollars and based on 2013 income levels, as recommended in Industrial Economics and Lisa Robinson $^{45}$.

Capital damages estimation. The estimation of capital damages mainly requires two types of basic data, i.e., the number of each type of buildings damaged or destroyed by wildfires and the repairing or reconstruction cost of these structures. The former, structure damage situation, is mainly derived from the National Large Incident Year-to-Date Report ${ }^{14}$, issued by the National Interagency Fire Center of the US. The California Fire official website provides more detailed statistics or maps for some major wildfires. For the reconstruction cost of buildings in different parts of California, we refer to Allstate (https://www.insurancejournal.com/news/west/2018/12/13/512021.htm), Corelogic (https://www.insurancejournal.com/news/west/2018/11/16/509534.htm), and Munich RE ${ }^{15}$. Their reports on Insurance Journal provide the number and total reconstruction cost value of buildings within the perimeter of the major fires. We calculated the average reconstruction cost of the buildings in different regions based on it. For the damaged structure, we assume that the repairing cost of partially damaged structures is $50 \%$ of its reconstruction cost and this ratio range from $1 \%$ to $99 \%$ in the uncertainty analysis.

Indirect economic impact assessment. The direct losses are used as negative shocks of our Multi-Regional Disaster Footprint (MRDF) model to assess the indirect economic impact of wildfires on the economic system. MRDF model is an extension of the Adaptive Regional Input-Output (ARIO) model proposed by Hallegate ${ }^{18}$, which has been wildly used in disaster impact assessment ${ }^{11,19,20}$ due to its ability to take into account both changes in production capacity due to productive capital losses and adaptive behavior in disaster aftermaths simultaneously in the IO framework. We extend the ARIO model to a multi-regional case on the basis of the multiregional input-output (MRIO) analysis and the linear programming (LP) technique. Linking the improved model with the latest MRIO table for California, we assessed the output losses of industrial sectors in different regions caused by the supply-chain disruption triggered by the initial wildfire shocks. 
To estimate the indirect costs of wildfires under the input-output framework, we first compiled a MRIO table for the study subjects. There are 59 region in the MRIO table, including 58 counties in California and an aggregation region, i.e., the Rest of United States (RoUS). Production activities in each region are divided into 80 industrial sectors (see Supplementary Table 3) and each sector produce one unique commodity. The basic data required to create the raw MRIO table came from IMPLAN, including the regional IO table, the import matrix for each county and RoUS, and the trade flow data for each commodity between the regions. We use the "Chenery-Moses" approach ${ }^{47}$ for consistent estimation of the intra- and interregional transections and the RAS method for balancing the raw MRIO table.

We assume that the economy before the wildfires is in a stable state and can be expressed by equation (1), i.e., the standard open input-output model developed by Leontief,

$$
\mathbf{x}=\mathbf{A x}+\mathbf{f}
$$

Where $\mathbf{x}$ is a column vector of dimension $N \times M$ (where $M$ is the number of industrial sectors and $N$ is the number of regions) representing the total production of each industrial sector in each region, Ax represents the intermediate demand vector, where each element of the matrix $\mathbf{A},\left[a_{r s i j}\right]$, refers to the technical relation showing product $i$ in region $r$ needed to produce one unit of product $j$ in region $s$. $\mathbf{f}$ indicates final demand vector of products. This standard model exactly replicates the equilibrium without disruptions.

When an economy is hit by a disaster, some part of its productive capacity is lost due to productive constrains, including productive capital loss, productive time loss, and transportation constraints. These constraints will first lead to production declines of industrial sectors that directly affected by the disaster, and then this initial production decline can trigger both forward and backward effects ${ }^{19,20}$ through the intra- and inter-regional industrial linkages.

Another important aspect to model the disaster aftermath is the reconstruction demand from the affected economy. Producers that affected by the disaster directly want to restore their production capacity by reconstruct their destroyed buildings or repair their damaged buildings. To do that, inductrial sectors need reconstruction resource from construction sector or manufacturing sector. Following Hallegate ${ }^{18,19}$, we assume that damages in each sector create an additional demand of $75 \%$ of the damage value to the construction sector and of $25 \%$ of the damage value to the manufacturing sector. The reconstruction demand of industrial $i$ in region $r$ to industrial $j$ in region $s, f_{r, s, i, j, t}^{R D}$, can be calculated as follows, 


$$
f_{r, s, i, j, t}^{R D}=\left\{\begin{aligned}
0, & k_{r, i, t}^{\Delta} \geq k_{r, i, 0} \\
d_{j} \times\left(k_{r, i, 0}-k_{r, i, t}^{\Delta}\right) \times \frac{x_{s, j, t}}{\sum_{s s, j j} x_{s s, j j, t}}, & k_{r, i, t}^{\Delta}<k_{r, i, 0}
\end{aligned}\right.
$$

Where $t$ denotes time, $i, j=1, \ldots M$ (M denotes the number of sectors), and $r, s=1, \ldots, N$ ( $N$ denotes the number of regions), $k_{r, i, t}^{\Delta}$ denotes capital stock of industrial sector $i$ in region $r$ in time step $t, d_{j}$ denotes the distribution coefficients, $x_{s, j, t}$ denotes the output of industrial sector $j$ in region $s$ in time step $t$.

We assume that each industry sector will try their best to meet the demands from its clients under the current constraints. A linear programming (LP) technique are used to represent the production behavior of industrial sectors with productive capacity constraints in each period ${ }^{48}$. The LP problem can be described by the following set of equations. A full list of all variables and their description can be found in Supplementary Table 4.

$$
\max \boldsymbol{i}^{\prime} \boldsymbol{x}_{\boldsymbol{t}}=\sum_{s, j} x_{s, j, t}
$$

Subject to the following production side constraints (i-vi),

(i) the production technology constraints (the production functions),

$$
x_{s, j, t}=\min \left\{\forall i, \frac{z_{r, s, i, j, t}}{a_{r, s, i, j}} ; \forall u, \frac{v_{u, s, j, t}}{b_{u, s, j}}\right\}
$$

(ii) the productive capital constraints,

$$
v_{k, s, j, t} \leq\left(\frac{k_{s, j, t}}{k_{s, j, 0}}\right) \times v_{k, s, j, 0}
$$

(iii) the working time constraints,

$$
v_{l, s, j, t} \leq\left(\frac{l_{s, j, t}}{l_{s, j, 0}}\right) \times v_{l, s, j, 0}
$$

(iv) the transportation constraints,

$$
z_{r, s, i, j, t} \leq\left(\frac{p_{r, t}}{p_{r, 0}}\right) \times z_{r, s, i, j, 0}
$$

And, the following demand side constraints,

(v) the intermediate demand constraints,

$$
\sum_{r, i} z_{r, s, i, j, t} \leq x_{s, j, t}
$$


(vi) the total demand constraints,

$$
x_{s, j, t} \leq \sum_{r, i} z_{r, s, i, j, t}+\sum_{r} f_{r, s, j, t}^{D}+\sum_{r, i} f_{r, s, i, j, t}^{R D}
$$

where $z_{r, s, i, j, t}$ denotes the intermediate demand of industrial $i$ in region $r$ to industrial $j$ in region $s, f_{r, s, j, t}^{D}$ denotes the final demand of households in region $r$ to industrial $j$ in region $s$. The solution of the LP problem determined the output of each sector in each region, i.e., $x_{s, j, t}$, which will be distribute into: first (i) the intermediate consumption demand, which is determined in the LP solution, and then (ii) other demand, i.e. final demand and reconstruction demand. If the output of a industrial sector can not meet the demands from its clients, a proportional rationing scheme will be applied ${ }^{18,19}$. The products will be allocated to the clients according to their proportion of demand.

In our improved model, production capacity will not be restored immediately as the reconstruction resources are filled, but with some delay. Reconstruction of production plant takes time. We record the recovered resources as construction in progress, which did not play any role in the production process. The average time to build a building in California takes about 4-8 months. Considering that the speed of post-disaster reconstruction may be faster than usual, in this study, we made a less severe assumption that the construction of the buildings will take 90 days. In other words, the corresponding production capacity will be restored after the reconstruction resource are received.

The dynamic of another two supply side constraints are modeled as follows: for transportation, we assume that transportation in the area that directly affected by fires will be disrupted immediately and the lockdown will gradually be released within the next few days. For labor, the availability of labor is constrained by transportation disruption and fire pollution-induced disease admission. The former is parallel with the transportation disruption and the latter is derived from the simulation results of BenMAP.

The economy will recover to the pre-disaster equilibrium after all constraints are lifted. We define the value-added decrease of each industrial sector in a network caused by an exogenous negative shock as the disaster impacts of the shock. Note that, we aim to assess the potential losses due to only the wildfires. Therefore, other factors, e.g., technology, were remain unchanged. In this way, we separately extract the effects of disaster shocks. The indirect economic cost, $E C$, is calculated as

$$
E C_{s, j}=\sum_{u} v_{u, s, j, 0} \times T-\sum_{u, t} v_{u, s, j, t}
$$


where $T$ represents the total time step used to recovery to the pre-crisis equilibrium, and $u$ presents the type of primary inputs, $l$ or $k$.

\section{Data availability}

Ground-level PM2.5 measurements for 2018 were obtained from U.S. Environmental Protection Agency's Air Quality System (https://www.epa.gov/outdoor-air-quality-data/); MAIAC AOD was downloaded from NASA Earthdata portal (https://search.earthdata.nasa.gov/); North American Land Data Assimilation Systems, elevation at $30 \mathrm{~m}$ spatial resolution from the National Elevation Data set (NED, http://ned.usgs.gov); forest cover, shrub cover and cultivated land cover at $30 \mathrm{~m}$ spatial resolution from the 2011 National Land Cover Database (NLCD, http://www.mrlc.gov); Road lengths of major roads, highways and interstate highways extracted from ESRI StreetMap USA (Environmental Systems Research Institute, Inc., Redland, CA); the population data from 2017 LandScan data (https://landscan.ornl.gov/downloads/2017); wildland fire information from the National interagency Fire Center (National Large Incident Year-to-Date Report 2018), CAL FIRE (https://www.fire.ca.gov/); asset loss data calculated based on reports from Munich RE (https://www.munichre.com/en/mediarelations/publications/press-releases/2019/2019-01-08-press-release/index.html); the county level input-output table and trade flow data between counties from IMPLAN (https://implan.com/data/).

\section{Code availability}

The simulation code for the indirect economic costs can be accessed at https://github.com/DaopingW/Disaster-Footprint-Model. The minimal input for the code is multiregional input-output table. The sample code and test data for the minimal inputs are also provided.

\section{References}

1 Abatzoglou, J. T. \& Williams, A. P. Impact of anthropogenic climate change on wildfire across western US forests. Proceedings of the National Academy of Sciences 113, 11770-11775, doi:10.1073/pnas.1607171113 (2016).

2 Dennison, P. E., Brewer, S. C., Arnold, J. D. \& Moritz, M. A. Large wildfire trends in the western United States, 1984-2011. Geophysical Research Letters 41, 2928-2933, doi:10.1002/2014g1059576 (2014). 
Holden, Z. A. et al. Decreasing fire season precipitation increased recent western US forest wildfire activity. Proceedings of the National Academy of Sciences 115, E8349, doi:10.1073/pnas.1802316115 (2018).

Kitzberger, T., Falk, D. A., Westerling, A. L. \& Swetnam, T. W. Direct and indirect climate controls predict heterogeneous early-mid 21st century wildfire burned area across western and boreal North America. PLOS ONE 12, e0188486, doi:10.1371/journal.pone.0188486 (2017).

Latif, M. T. et al. Southeast Asian Forest Fires (1997/1998): El Niño as a Driver of Regional Impacts. Air Pollution Episodes 6, 191 (2017).

Balch, J. K. et al. Human-started wildfires expand the fire niche across the United States. Proceedings of the National Academy of Sciences 114, 2946, doi:10.1073/pnas.1617394114 (2017).

Radeloff, V. C. et al. Rapid growth of the US wildland-urban interface raises wildfire risk. Proceedings of the National Academy of Sciences 115, 3314-3319 (2018).

Zhuang, J., Payyappalli, V. M., Behrendt, A. \& Lukasiewicz, K. Total cost of fire in the United States. (Fire Protection Research Foundation, 2017).

Shi, H. et al. Modeling Study of the Air Quality Impact of Record-Breaking Southern California Wildfires in December 2017. Journal of Geophysical Research: Atmospheres 124, 6554-6570, doi:10.1029/2019jd030472 (2019).

Reid Colleen, E. et al. Critical Review of Health Impacts of Wildfire Smoke Exposure. Environmental Health Perspectives 124, 1334-1343, doi:10.1289/ehp.1409277 (2016).

11 Inoue, H. \& Todo, Y. Firm-level propagation of shocks through supply-chain networks. Nature Sustainability 2, 841-847, doi:10.1038/s41893-019-0351-x (2019).

12 Rose, A., Benavides, J., Chang, S. E., Szczesniak, P. \& Lim, D. The Regional Economic Impact of an Earthquake: Direct and Indirect Effects of Electricity Lifeline Disruptions. Journal of Regional Science 37, 437-458, doi:10.1111/0022-4146.00063 (1997).

13 Johnston Fay, H. et al. Estimated Global Mortality Attributable to Smoke from Landscape Fires. Environmental Health Perspectives 120, 695-701, doi:10.1289/ehp.1104422 (2012).

14 National Interagency Fire Center. 2018 National Year-to-Date Report on Fires and Acres Burned. (2018).

15 Munich RE. <https://www.munichre.com/en/media-relations/publications/press-releases/2019/201901-08-press-release/index.html $>($

16 Randerson, J. T., Van Der Werf, G. R., Giglio, L., Collatz, G. J. \& Kasibhatla, P. S. Global Fire Emissions Database, Version 4.1 (GFEDv4). ORNL Distributed Active Archive Center, doi:10.3334/ORNLDAAC/1293 (2017).

17 Sacks, J. D. et al. The Environmental Benefits Mapping and Analysis Program - Community Edition (BenMAP-CE): A tool to estimate the health and economic benefits of reducing air pollution. Environmental Modelling \& Software 104, 118-129, doi:https://doi.org/10.1016/j.envsoft.2018.02.009 (2018).

18 Hallegatte, S. An Adaptive Regional Input-Output Model and its Application to the Assessment of the Economic Cost of Katrina. Risk Analysis 28, 779-799, doi:10.1111/j.1539-6924.2008.01046.x (2008).

19 Hallegatte, S. Modeling the Role of Inventories and Heterogeneity in the Assessment of the Economic Costs of Natural Disasters. Risk Analysis 34, 152-167, doi:10.1111/risa.12090 (2014).

20 Guan, D. et al. Global supply-chain effects of COVID-19 control measures. Nature Human Behaviour 4, 577-587, doi:10.1038/s41562-020-0896-8 (2020).

21 Shen, E., Oliver, A. \& Dabirian, S. Final Socioeconomic Report Appendices to the 2016 Air Quality Management Plan. (South Coast Air Quality Management District., http://www.aqmd.gov/docs/default-source/clean-air-plans/socioeconomicanalysis/final/sociofinal 030817.pdf?sfvrsn=2, 2017). 
Davidson, K., Hallberg, A., McCubbin, D. \& Hubbell, B. Analysis of PM2.5 Using the Environmental Benefits Mapping and Analysis Program (BenMAP). Journal of Toxicology and Environmental Health, Part A 70, 332-346, doi:10.1080/15287390600884982 (2007). prospective study. (https://www.epa.gov/clean-air-act-overview/benefits-and-costs-clean-air-act-19902020-second-prospective-study, 2011).

24 Jazebi, S., León, F. d. \& Nelson, A. Review of Wildfire Management Techniques_Part I: Causes, Prevention, Detection, Suppression, and Data Analytics. IEEE Transactions on Power Delivery 35, 430-439, doi:10.1109/TPWRD.2019.2930055 (2020).

25 Roberts, D. California's deliberate blackouts were outrageous and harmful. They're going to happen again., (https://www.vox.com/energy-and-environment/2019/10/16/20910947/climate-changewildfires-california-2019-blackouts, 2019).

26 Smith, A. E. \& Gans, W. Enhancing the Characterization of Epistemic Uncertainties in PM2.5 Risk Analyses. Risk Anal 35, 361-378, doi:10.1111/risa.12236 (2015).

27 Xiao, Q., Chang, H. H., Geng, G. \& Liu, Y. An Ensemble Machine-Learning Model To Predict Historical PM2.5 Concentrations in China from Satellite Data. Environmental Science \& Technology 52, 13260-13269, doi:10.1021/acs.est.8b02917 (2018).

28 Stowell, J. D. et al. Associations of wildfire smoke PM2.5 exposure with cardiorespiratory events in Colorado 2011-2014. Environment International 133, 105151, doi:https://doi.org/10.1016/j.envint.2019.105151 (2019).

29 Lyapustin, A., Martonchik, J., Wang, Y., Laszlo, I. \& Korkin, S. Multiangle implementation of atmospheric correction (MAIAC): 1. Radiative transfer basis and look-up tables. Journal of Geophysical Research: Atmospheres 116, doi:10.1029/2010JD014985 (2011).

30 Lyapustin, A. et al. Multiangle implementation of atmospheric correction (MAIAC): 2. Aerosol algorithm. Journal of Geophysical Research: Atmospheres 116, doi:10.1029/2010JD014986 (2011).

31 Chen, H., Goldberg, M. S. \& Villeneuve, P. J. A systematic review of the relation between long-term exposure to ambient air pollution and chronic diseases. Rev Environ Health 23, 243-297, doi:10.1515/reveh.2008.23.4.243 (2008).

32 Kampa, M. \& Castanas, E. Human health effects of air pollution. Environmental Pollution 151, 362367, doi:https://doi.org/10.1016/j.envpol.2007.06.012 (2008).

33 Pascal, M. et al. Assessing the public health impacts of urban air pollution in 25 European cities: results of the Aphekom project. Sci Total Environ 449, 390-400, doi:10.1016/j.scitotenv.2013.01.077 (2013).

34 Driscoll, C. T. et al. US power plant carbon standards and clean air and health co-benefits. Nature Climate Change 5, 535-540, doi:10.1038/nclimate2598 (2015).

35 Zhu, S., Horne, J. R., Mac Kinnon, M., Samuelsen, G. S. \& Dabdub, D. Comprehensively assessing the drivers of future air quality in California. Environment International 125, 386-398, doi:10.1016/j.envint.2019.02.007 (2019).

36 Jones, B. A., Thacher, J. A., Chermak, J. M. \& Berrens, R. P. Wildfire smoke health costs: a methods case study for a Southwestern US 'mega-fire'. Journal of Environmental Economics and Policy 5, 181199, doi:10.1080/21606544.2015.1070765 (2016).

37 Jones, B. A. \& Berrens, R. P. Application of an Original Wildfire Smoke Health Cost Benefits Transfer Protocol to the Western US, 2005-2015. Environmental Management 60, 809-822, doi:10.1007/s00267-017-0930-4 (2017).

38 Rose, A. N., McKee, J. J., Urban, M. L. \& Bright, E. A. LandScan (Oak Ridge National Laboratory, Oak Ridge, TN, 2018).

39 Industrial Economics. Review of Baseline Incidence Rate Estimates for Use in 2016 Socioeconomic Assessment. (Massachusetts, MA: Industrial Economics, Inc., http://www.aqmd.gov/docs/default- 
source/clean-air-plans/socioeconomicanalysis/iecmemos_november2016/scbaselineincidence_112916.pdf, 2016).

40 Industrial Economics. Literature Review of Air Pollution-Related Health Endpoints and ConcentrationResponse Functions for Particulate Matter: Results and Recommendations., (Cambridge, MA:

Industrial Economics, Inc., http://www.aqmd.gov/docs/default-source/clean-air-plans/socioeconomicanalysis/iec_pmlitreview_092916.pdf, 2016).

41 Industrial Economics. Literature Review of Air Pollution-Related Health Endpoints and ConcetnrationResponse Functions for Ozone, Nitrogen Dioxide, and Sulfur Dioxide: Results and Recommendations., (Cambridge, MA: Industrial Economics, Inc., http://www.aqmd.gov/docs/default-source/clean-airplans/socioeconomic-analysis/iec gasplitreview 092916.pdf. Available at: http://www.aqmd.gov/docs/default-source/clean-air-plans/socioeconomicanalysis/iec_pmlitreview 092916.pdf, 2016).

42 Jerrett, M. et al. Spatial analysis of air pollution and mortality in California. Am J Respir Crit Care Med 188, 593-599, doi:10.1164/rccm.201303-0609OC (2013).

43 Krewski, D. et al. Extended follow-up and spatial analysis of the American Cancer Society study linking particulate air pollution and mortality. Res Rep Health Eff Inst, 5-114; discussion 115-136 (2009).

44 Industrial Economics \& Lisa Robinson. Review of Morbidity Valuation Estimates for Use in 2016 Socioeconomic Assessment. (Massachusetts, MA: Industrial Economics, Inc., http://www.aqmd.gov/docs/default-source/clean-air-plans/socioeconomicanalysis/iecmemos november2016/scmorbidityvaluation 112816.pdf, 2016).

45 Industrial Economics \& Lisa Robinson. Review of Mortality Risk Reduction Valuation Estimates for 2016 Socioeconomic Assessment. (Massachusetts, MA: Industrial Economics, Inc., http://www.aqmd.gov/docs/default-source/clean-air-plans/socioeconomicanalysis/iecmemos_november2016/evaluationcriteria_113016.pdf, 2016).

46 Robinson, L. A. \& Hammitt, J. K. Valuing Reductions in Fatal Illness Risks: Implications of Recent Research. Health Econ 25, 1039-1052, doi:10.1002/hec.3214 (2016).

47 Miller, R. E. \& Blair, P. D. Input-Output Analysis: Foundations and Extensions. 2 edn, (Cambridge University Press, 2009).

48 Koks, E. E. \& Thissen, M. A Multiregional Impact Assessment Model for disaster analysis. Economic Systems Research 28, 429-449, doi:10.1080/09535314.2016.1232701 (2016).

49 Mintz, D. Technical assistance document for the reporting of daily air quality-the air quality index (aqi): US environmental protection agency. Office of Air Quality Planning and Standards, 1-26 (2018).

Correspondence and requests for materials should be addressed to D.G.

\section{Acknowledgements}

This study was supported by the National Key R\&D Program of China (2016YFA0602604), National Natural Science Foundation of China (41921005, 91846301, 41629501, 71922015 and 71773075), the UK Natural Environment Research Council (NE/N00714X/1 and NE/P019900/1), the Economic and Social Research Council (ES/L016028/1), British Academy (NAFR2180103). 


\section{Competing interests}

The authors declare no competing interests.

\section{Author contributions}

D.G. and S.J.D. designed the study. D.W., S.Z., G.G., and M.M. performed the analysis.

D.G., S.J.D. and D.W. interpreted the results. D.W., S.J.D., and T.L. prepared the figures.

D.W., S.J.D., D.G., S.Z. and G.G. prepared the manuscript. D.W., S.Z., G.G., T.L. and H.Z. prepared the supplementary information. D.G. coordinated and Q.Z. and P.G. supervised the project. Q.Z., S.S., and P.G. participated in the writing of the manuscript.

\section{Figure Legends}

Figure 1. Air pollution due to fire emissions from July to December in California. a-f, show monthly mean $\mathrm{PM}_{2.5}$ concentrations induced by fire emissions (Maps in the top panel of each subfigure), the area in each air quality index category in California (Bar charts in the bottom panel of each subfigure; Please refer to Mintz ${ }^{49}$ for the criteria); data for county boundary lines come from Geography Program of United States Census Bureau (www.census.gov/programs-surveys/geography.html). In the maps, pollutant concentrations from low to high are indicated using shades from cool colour to warm colour (blue-yellow-red). In the bar charts, the area statistics in each air quality category are shown in stacked bar charts (some grids on simulated boundaries, outside California, are counted). Wildfires in July, August, September, and November release large amounts of pollutants into the air (maps; a,b,c,e): from July to September, wildfires in northern California (e.g., the Carr fire in Shasta County from July 23 to August 29; the Mendocino complex fire in Colusa, Glenn, Lake, and Mendocino County from July 28 to September 17; Table 1, Supplementary Figure 1) and the Sierra Nevada (e.g., the Ferguson fire in Mariposa County from July 14 to August 23; the Lions fire in Madera County from June 23 to September 6) caused monthly concentrations of local air pollutants to increase by more than $10 \mathrm{ug} / \mathrm{m}^{3}$ (up to about $60 \mathrm{ug} / \mathrm{m}^{3}$ ) (maps; a,b,c); In November, the Camp fire in butte county (northern California) considerable increased the concentration of pollutants in the air (e). Fire pollutants can spread over great distances, resulting in poor air quality in unburned areas (bars; a,b,c,e): from late July to early September and mid-November, air quality in many areas of California was not in the "good" category $\left(0-15.4 \mathrm{ug} / \mathrm{m}^{3}\right)$. Note that, the area in the bar charts includes the boundary the model area.

Figure 2. Fire-related damages from the 2018 wildfires in California. a-h, Map shows the county-level Capital loss (a; in units of millions of dollar), capital loss per capita (b; in units of dollar per person), the county-level health cost (c), health cost per capita (d), the county-level indirect loss (e), indirect loss per capita (f), county-level total damages (g), and total damages per capita (h). Data for county boundary lines come from Geography Program of United States Census Bureau. 
Figure 3. Impacts of wildfires on specific industry sectors in California. a, ternary plot shows the magnitude of 2018 fire impacts on specific industry sectors in California (size of circles) as well as the relative shares of capital losses, health costs, and indirect losses (position of circles). b-d, ternary plot shows the losses in each subsectors in Services (b), Manufacturing (c), and Trade (d). See figure S5-S8 and Table S2 for damages in other subsectors.

\section{Tables}

Table 1. Seventeen largest fires by area burned in California in 2018

\begin{tabular}{|c|c|c|c|c|c|c|c|}
\hline Name & Cause & $\begin{array}{l}\text { Start } \\
\text { Date }\end{array}$ & End Date & County & $\begin{array}{r}\text { Size } \\
\text { (Acres) }\end{array}$ & $\begin{array}{r}\text { Suppression } \\
\text { Costs (M\$) }\end{array}$ & $\begin{array}{l}\text { Structures } \\
\text { Destroyed }\end{array}$ \\
\hline Pawnee & Human & 23-Jun & 7-Jul & Lake & 15,185 & 36.5 & 22 \\
\hline Lions & Lightning & 23-Jun & 6-Sep & Madera & 12,990 & 13.9 & 0 \\
\hline Waverly & Unclear & 29-Jun & 2-Jul & San Joaquin & 11,789 & 2.5 & 3 \\
\hline County & Human & 30-Jun & 13-Jul & Yolo & 90,288 & 46.9 & 30 \\
\hline Klamathon & Unclear & 5-Jul & 21-Jul & Siskiyou & 38,008 & 33.5 & 82 \\
\hline Ferguson & Unclear & 14-Jul & 23-Aug & Mariposa & 9,6901 & 118.5 & 11 \\
\hline Carr & Human & 23-Jul & 29-Aug & Shasta & 22,9651 & 158.8 & 1604 \\
\hline Cranston & Human & 25-Jul & 8-Aug & Riverside & 13,139 & 22.1 & 12 \\
\hline Whaleback & Unclear & 27-Jul & 6-Aug & Lassen & 1,8703 & 8.9 & 0 \\
\hline $\begin{array}{r}\text { Mendocino } \\
\text { Complex }\end{array}$ & Unclear & 28-Jul & 17-Sep & $\begin{array}{r}\text { Colusa, Glenn, } \\
\text { Lake, } \\
\text { Mendocino }\end{array}$ & 459,123 & 201.0 & 280 \\
\hline Donnell & Unclear & 2-Aug & 6-Sep & Tuolumne & 3,6450 & 33.6 & 135 \\
\hline Holy & Unclear & 6-Aug & 3-Sep & $\begin{array}{l}\text { Orange, } \\
\text { Riverside }\end{array}$ & 23,025 & 25.70 & 24 \\
\hline Hirz & Human & 9-Aug & 13-Sep & Shasta & 46,150 & 55.5 & 0 \\
\hline Stone & Lightning & 15-Aug & 29-Aug & Modoc & 39,387 & 16.9 & 2 \\
\hline Delta & Human & 5-Sep & 6-Oct & Shasta & 63,311 & 64.4 & 45 \\
\hline Camp & Unclear & 8-Nov & $25-\mathrm{Nov}$ & Butte & 153,336 & 102.8 & 18804 \\
\hline Woolsey & Unclear & 8-Nov & 20-Nov & $\begin{array}{r}\text { Los Angeles, } \\
\text { Ventura }\end{array}$ & 96,949 & 56.9 & 1643 \\
\hline
\end{tabular}

Source: US National Large Incident Year-to-Date Report 2018. 